\title{
Uso de expansores tisulares a modo de soporte cutáneo. Presentación de un nuevo dispositivo
}

\author{
Tissue expanders as cutaneous support. \\ Presentation of a new device
}

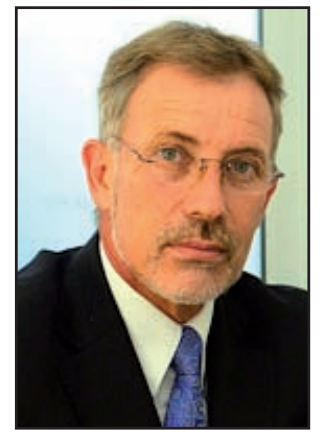

Moretti, E.

Moretti, E.*

\section{Resumen}

Presentamos a la comunidad médica un nuevo dispositivo de diseño personal para uso en reconstrucción mamaria bilateral. Es similar a un expansor tisular, pero posee como diferencias un tubo conector de $3,3 \mathrm{~mm}$ de diámetro interno y $5 \mathrm{~mm}$ de diámetro externo, pico Lubber para conexión directa a jeringa y sin válvula. El sistema ha sido diseñado por el Departamento de Ingeniería de la fábrica Nagor $^{\circledR}$, Cumbernauld, Escocia, Reino Unido, siguiendo las indicaciones del autor.

Su uso se limita a casos de mastectomía con conservación de tejidos (mastectomía con conservación de piel, mastectomía con conservación de areola-pezón) y mastectomía para reducción de riesgo (adenomastectomía profiláctica), ya que su propósito es dar soporte tisular durante un corto período de tiempo (promedio de 10 días), hasta que se reciba el informe final histopatológico y se proceda al cambio por los implantes definitivos ajustados en tamaño y simetría.

Presentamos resultados en 30 casos en los que el dispositivo se ha usado de forma bilateral.

\author{
Palabras clave Reconstrucción mamaria, \\ Expansores tisulares, \\ Mastectomía, Adenomastectomía.
}

Nivel de evidencia científica
4

\section{Key words Breast reconstruction, \\ Tissue expanders, Mastectomy, Adenomastectomy.}

Level of evidence
Abstract

A new device to be used in bilateral breast reconstructions is presented to the medical community. The device is similar to a tissue expander, but has a $5 \mathrm{~mm}$ connector tube (3,3 $\mathrm{mm}$ inside), with a Lubber tip with direct syringe connection and it has no valve. With the co-operation of the Department of Engineering at Nagor Corp $^{\circledR}$, Cumbernauld, Scotland, United Kingdom, the new device was designed in line with the specifications drawn up by the author.

It is exclusively designed to be used in mastectomies with tissue preservation (skin sparing mastectomy, nipple-sparing mastectomy) and risk-reducing mastectomies (prophylactic adenomastectomies), since its purpose is to be used as a tissue support for a short period of time (average 10 days) until the final anatomical pathology report is received and thus the change is made for definitive implants, adjusted in size and symmetry.

We present the results in 30 cases using the new device in bilateral procedures. 


\section{Introducción}

En los últimos tiempos observamos un aumento mundial en la frecuencia del cáncer de mama, con detección en pacientes cada vez más jóvenes. La aparición de grupos de alto riesgo (pacientes portadoras de mutaciones del BRCA I y II, antecedentes familiares múltiples de cáncer de mama, mamas de difícil seguimiento, pacientes portadoras de cáncer de mama tratado con factores de alto riesgo asociado, etc) (1), así como el aumento de la cancerofobia que ha llevado a la exigencia por parte de las pacientes de la extirpación de sus mamas, han creado un sensible aumento de la cirugía de mastectomía bilateral en los últimos 2 años (2-3).

La indicación de una mastectomía bilateral o de una mastectomía unilateral con adenomastectomía profiláctica contralateral ha significado todo un nuevo desafío para los cirujanos plásticos.

El empleo de expansores y su posterior cambio por implantes definitivos es la técnica más utilizada para efectuar la reconstrucción mamaria inmediata $(75 \%)$ según la Sociedad Americana de Cirugía Plástica (4). Desde 1978, con Radovan (5-6), son numerosos los grupos con experiencia en reconstrucción inmediata que utilizan expansores anatómicos de superficie texturizada y con válvula incorporada o con válvula remota (7).

La colocación de un implante-expansor (modelo Becker) (8) no se indica con frecuencia ya que para su correcto uso se necesita una amplia curva de aprendizaje previa empleando expansores convencionales. Se utilizan en particular en casos de reconstrucción mamaria en los que hay probable dificultad para lograr la simetría y en situaciones especiales para reducir el número de tiempos quirúrgicos (9).

El motivo de esta publicación es presentar a la comunidad médica un nuevo dispositivo que posee las característica de un expansor tisular, con sus beneficios para estos casos, pero que funciona a modo de sostén o soporte de los tejidos cutáneos postmastectomía conservadora de piel y tras mastectomía de reducción de riesgo (adenomastectomía profiláctica), diseñado con la colaboración del Departamento de Ingeniería de la empresa Nagor Corp ${ }^{\circledR}$ (Cumbernauld, Escocia, Reino Unido), siguiendo las especificaciones realizadas por el autor.

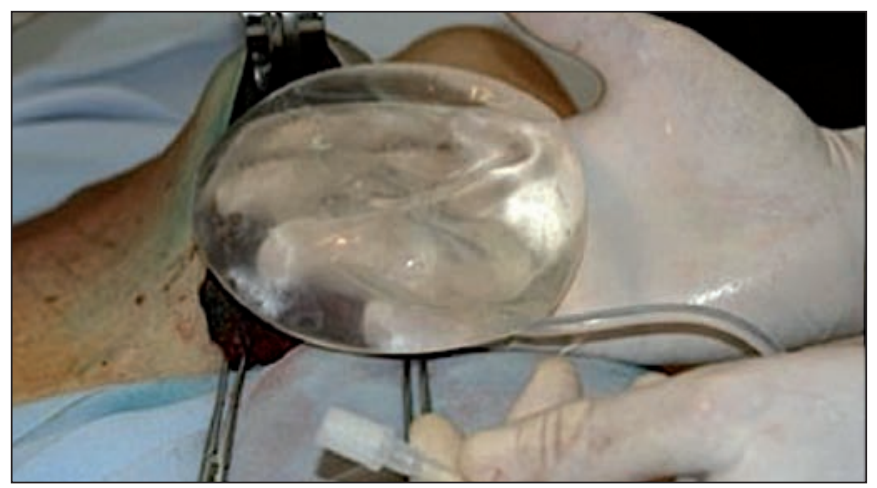

\section{Material y método}

\section{Descripción del dispositivo}

El dispositivo tiene las características de un expansor tisular de válvula remota similar a los tradicionalmente producidos por la empresa, de forma anatómica, superficie lisa, con modificaciones en el tubo conector. Dicho tubo pasa de una medida de $1,3 \mathrm{~mm}$ en su interior y $3,8 \mathrm{~mm}$ en su exterior, a ser un tubo de $3,3 \mathrm{~mm}$ en su interior y $5 \mathrm{~mm}$ en el exterior. En el extremo conector hemos colocado un pico tipo Lubber para conexión directa a jeringa. No tiene válvula (Fig. 1).

Los detalles técnicos de la pared del dispositivo siguen las especificaciones propias de fabricación de los expansores: 5 capas de silicona, capa barrera, pruebas de elongación que superan el valor 400 , todo ello de acuerdo con la información provista por el Departamento de Ingeniería de $\operatorname{Nagor}^{\circledR}(10)$. Los nuevos dispositivos se identifican por impresión con láser del número de lote y tamaño, se empaquetan y esterilizan por óxido de etileno. Poseen además la certificación CE para expansores obtenida por la empresa bajo el certificado CE 02248 (11).

Se fabricaron 60 dispositivos con volúmenes entre $335 \mathrm{cc}$ a $540 \mathrm{cc}$ para su empleo en el proyecto de investigación.

\section{Diseño del estudio}

En marzo del 2010 diseñamos un protocolo de investigación de fase clínica para empleo de los nuevos dispositivos en pacientes sometidas a procedimientos de reconstrucción mamaria bilateral tras cirugía oncológica inmediata.

Entre mayo del 2010 y mayo del 2012 tratamos 30 pacientes en las que efectuamos mastectomías con conservación de piel y mastectomías de reducción de riesgo (adenomastectomías profilácticas) en la mama contralateral, con colocación de nuestro dispositivo expansor de forma bilateral y simétrica en cada caso.

La edad promedio de las pacientes fue de 42 años (29 a 53 años). Todas fueron evaluadas previamente por el Comité de Tumores de nuestra institución y se acordó en todos estos casos efectuar el procedimiento quirúrgico de forma bilateral debido a diferentes factores: lesiones con-

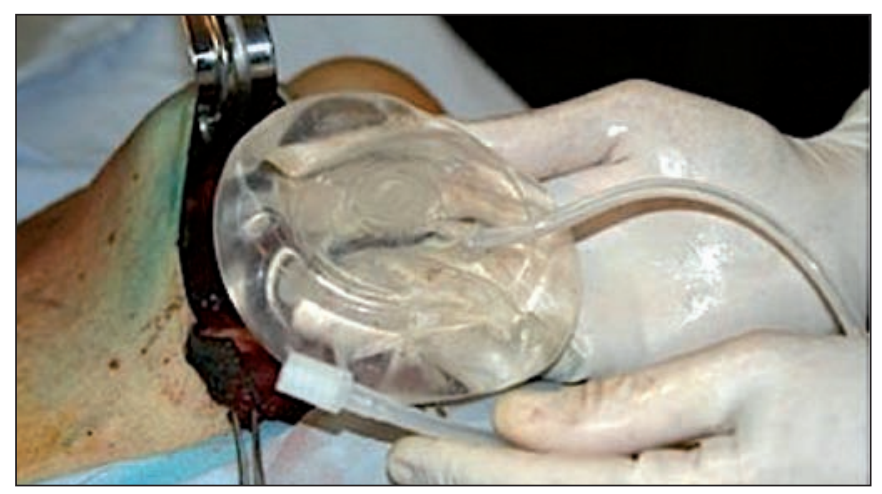

Fig. 1. Nuevo dispositivo diseñado como sistema transitorio para soporte de tejidos postadenomastectomía o mastectomía conservadora de piel. Características: superficie lisa, forma anatómica, tubo conector ancho de $5 \mathrm{~mm}$. de diámetro, pico Lubber y no posee válvula. 
tralaterales, mamas muy densas difíciles de controlar, microcalcificaciones, cancerofobia, etc.). En la mama con lesión maligna efectuamos estudio de ganglio centinela, y en la mama contralateral, en solo 4 casos, realizamos dicho procedimiento por indicación de Mastología.

En todos los casos se procedió a la extirpación del tejido mamario por parte del grupo quirúrgico oncólogomastólogo, ingresando el equipo reconstructivo al finalizar el tiempo oncológico. Al comenzar la etapa reconstructiva procedimos a disecar el bolsillo para la colocación del dispositivo; este bolsillo siempre fue parcialmente submuscular, debajo del músculo pectoral mayor. En todos los casos seccionamos las inserciones medias (internas) y bajas del músculo a la altura del $5^{\circ}$ espacio intercostal (Fig. 2). Esta sección completa interna logró la relajación muscular y permitió que el dispositivo alcanzara una mayor aproximación a la zona central esternal. Así mismo, en todos los procedimientos, colocamos una malla de poliglactina 910 (Vicryl ${ }^{\circledR}$ código VKMM) de 6" 6 6": 15 x $15 \mathrm{~cm}$ (12) suturada con el mismo material al borde inferior libre del músculo pectoral mayor (Fig. 3), y en el otro extremo al surco submamario. De esta manera, se cortó la malla y ocupó el espacio entre la

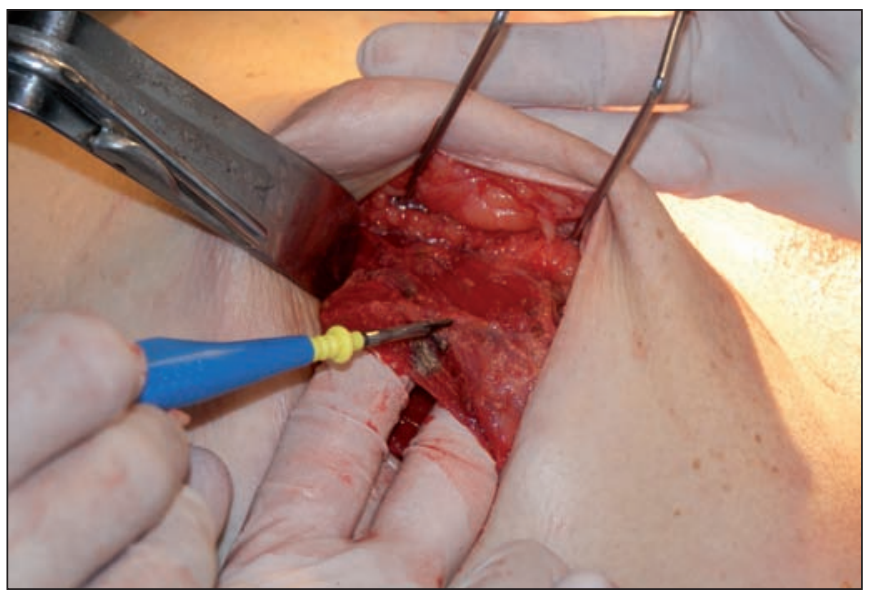

línea axilar anterior por fuera, el borde del músculo pectoral mayor por arriba, el surco submamario por abajo y la separación obtenida por la sección del pectoral internamente, en la parte medial. Logramos así el cierre del espacio submuscular parcial manteniendo el dispositivo en dicho lugar, evitando su migración al espacio dejado por la adenomastectomía y disminuyendo la retracción hacia arriba de las fibras del pectoral (Fig. 4).

En el grupo de estudio colocamos 60 dispositivos y exteriorizamos los tubos de llenado por contrabertura, extrayéndolos a nivel de la zona central de la incisión submamaria, para permitir así la ubicación correcta del dispositivo sin desplazamiento (Fig. 5). Los tamaños de los dispositivos variaron dependiendo del tejido extirpado calculado según principio de Arquímedes (Fig. 6), con un promedio de $435 \mathrm{cc}$ (entre 335 y $515 \mathrm{cc}$ ). A continuación, los llenamos con solución fisiológica estéril a través del tubo conector con jeringa tipo Lubber de $60 \mathrm{cc}$. Con el dispositivo expandido en su totalidad, efectuamos los ajustes necesarios en los bolsillos submusculares así como los ajustes de la malla de poliglactina 910 . De esta forma controlamos completamente el posicionamiento del dispositivo, la ubica-

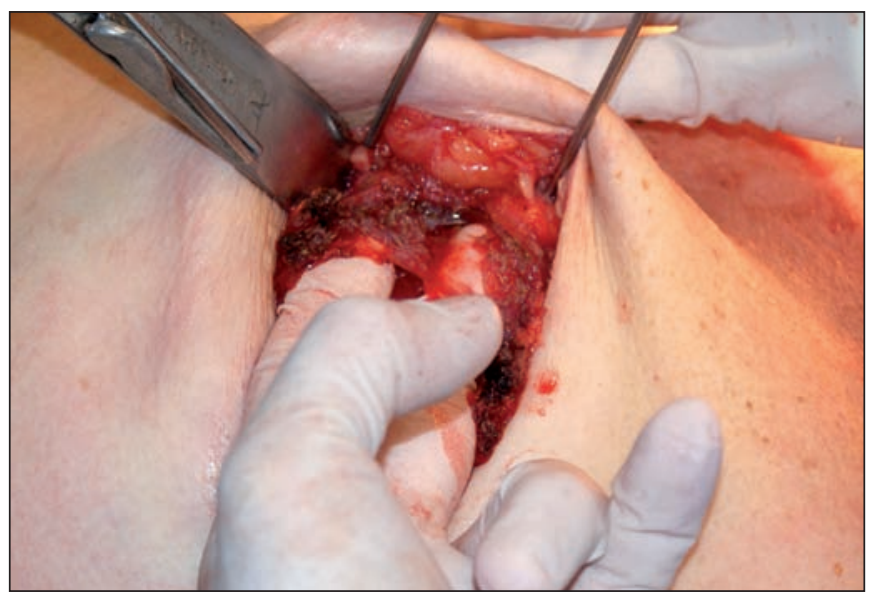

Fig. 2. Ubicación del dispositivo: plano submuscular parcial con sección de las fibras medias (internas) del músculo pectoral mayor.
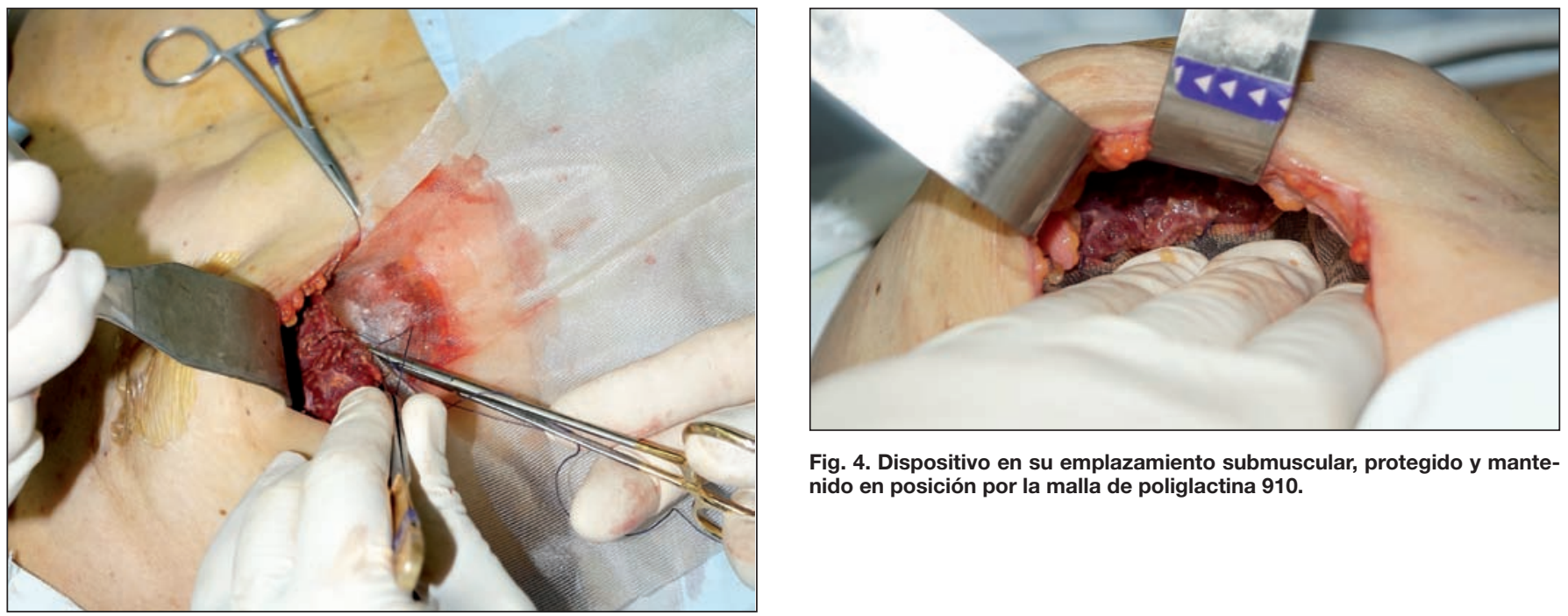

Fig. 4. Dispositivo en su emplazamiento submuscular, protegido y mantenido en posición por la malla de poliglactina 910.

Fig. 3. Colocación de malla de poliglactina 910 suturada al borde inferior del pectoral mayor para mantener el dispositivo en el plano profundo y evitar la retracción de las fibras musculares y el desplazamiento lateral. 
ción del músculo pectoral mayor y la tensión de la malla. También definimos correctamente el surco submamario y liberamos los tejidos próximos para tratar de obtener la mayor simetría posible. Una vez logrado dicho objetivo, procedimos a desinflar el dispositivo dejando solo un $20 \%$ del volumen total con el objeto de evitar la presión sobre los tejidos cutáneos (Fig. 710).

En todos los casos dejamos un drenaje en el lecho de la mastectomía y próximo al dispositivo, que se exteriorizó por contrabertura a nivel de la línea axilar anterior. Colocamos cura oclusiva en las incisiones quirúrgicas y alrededor de los drenajes y espuma de poliuretano sobre la superficie cutánea del tórax más un vendaje compresivo elástico suave.

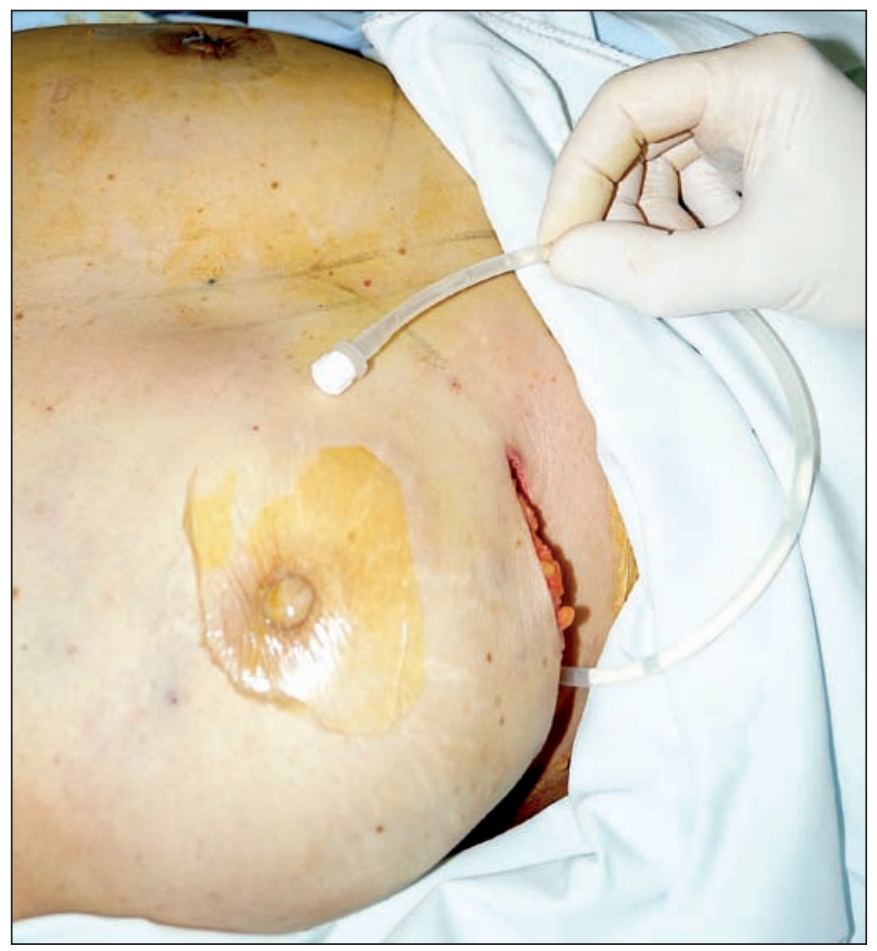

Fig. 5. Procedimiento finalizado: dispositivo colocado con exteriorización del tubo de llenado a través del surco submamario.

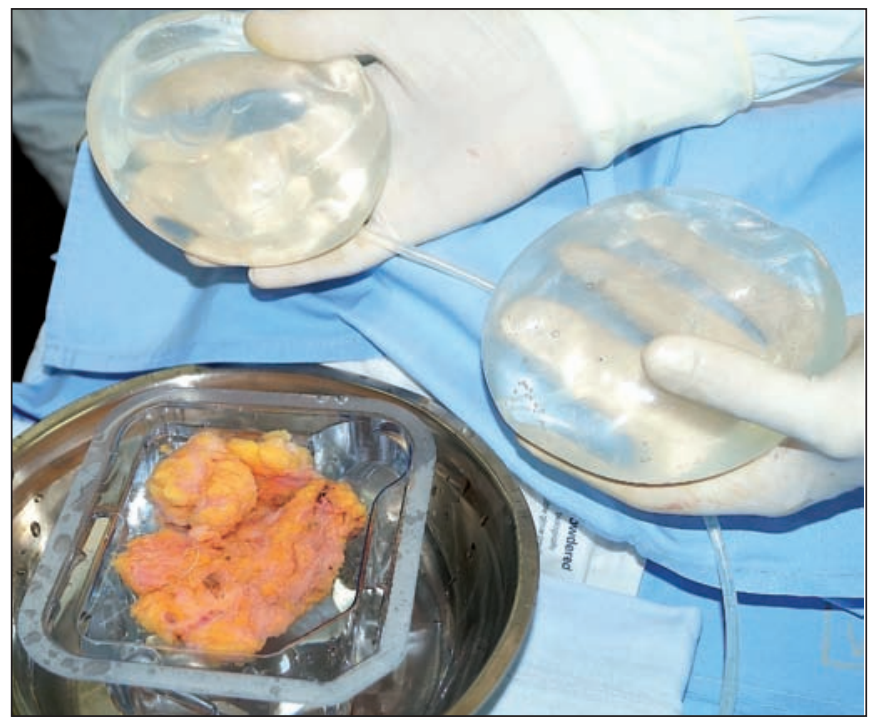

Todas las intervenciones se realizaron bajo anestesia general con intubación orotraqueal. El tiempo promedio de las cirugías fue de 3 horas, de las cuales 90 minutos correspondieron al acto reconstructivo propiamente dicho.

La cirugía fue bien tolerada en todos los casos siguiendo un internamiento hospitalario de 36 horas promedio (entre 24 a 48 horas). Todas las pacientes permanecieron en sala común con antibioticoterapia de tratamiento (cefadroxilo $500 \mathrm{mg}$ cada 12 horas hasta el momento de la segunda intervención quirúrgica), analgésicos convencionales, protectores gástricos (lanzoprazol), profilaxis de trombosis venosa profunda con vendajes elásticos en ambos miembros inferiores, enoxiheparina $40 \mathrm{mg}$ en dosis única diaria durante la hospitalización, y deambulación precoz. En el seguimiento posterior de las pacientes, retiramos los drenajes en un promedio de 4 días (entre 3 y 6 días).

Con respecto al comportamiento de los dispositivos, en la primera cura realizada en el momento del alta hospitalaria a las 36 horas de la intervención controlamos la vitalidad de los tejidos cutáneos y procedimos a la expansión según tolerancia al dolor. Los volúmenes utilizados en esta expansión fueron de $180 \mathrm{cc}$ como promedio en cada dispositivo (rango entre 120 a $240 \mathrm{cc}$ ). Las pacientes fueron controladas a los 5 y 7 días, momento en el que continuamos expandiendo. Los volúmenes colocados en estos 2 controles fueron de 90 a $120 \mathrm{cc}$ como promedio por dispositivo y en cada control, logrando así una expansión completa del sistema a los 7 días del postoperatorio (Fig. 11).

Una vez recibido el informe anatomo-patológico diferido por parte del grupo oncológico y estudiada nuevamente cada paciente por el Comité de Tumores de nuestra Institución para determinar la conducta a seguir en cada caso particular, procedimos a llevar a las pacientes nuevamente a quirófano para efectuar el recambio de los dispositivos expansores por los implantes definitivos, así

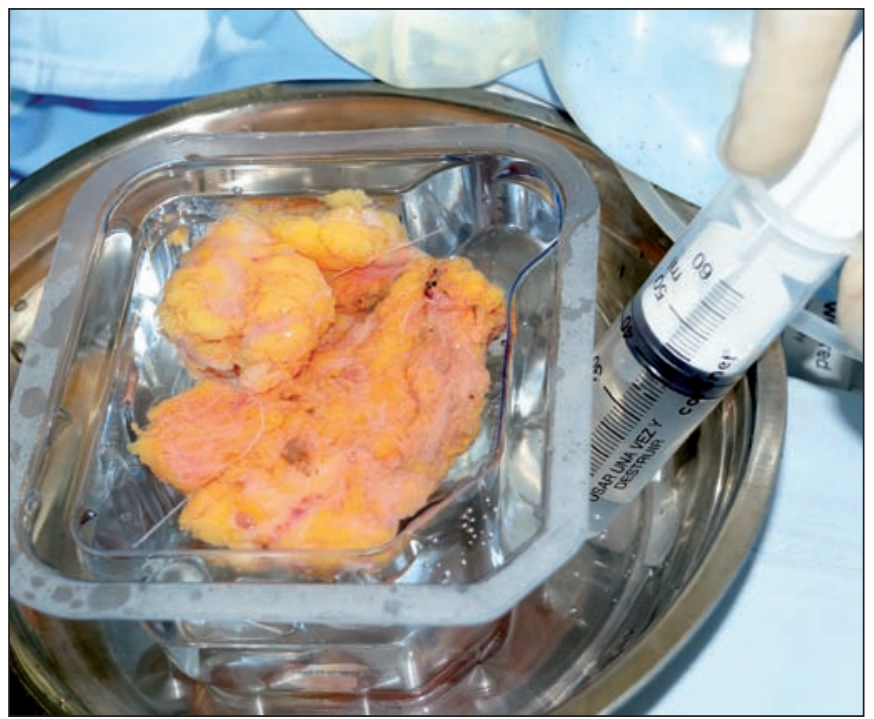



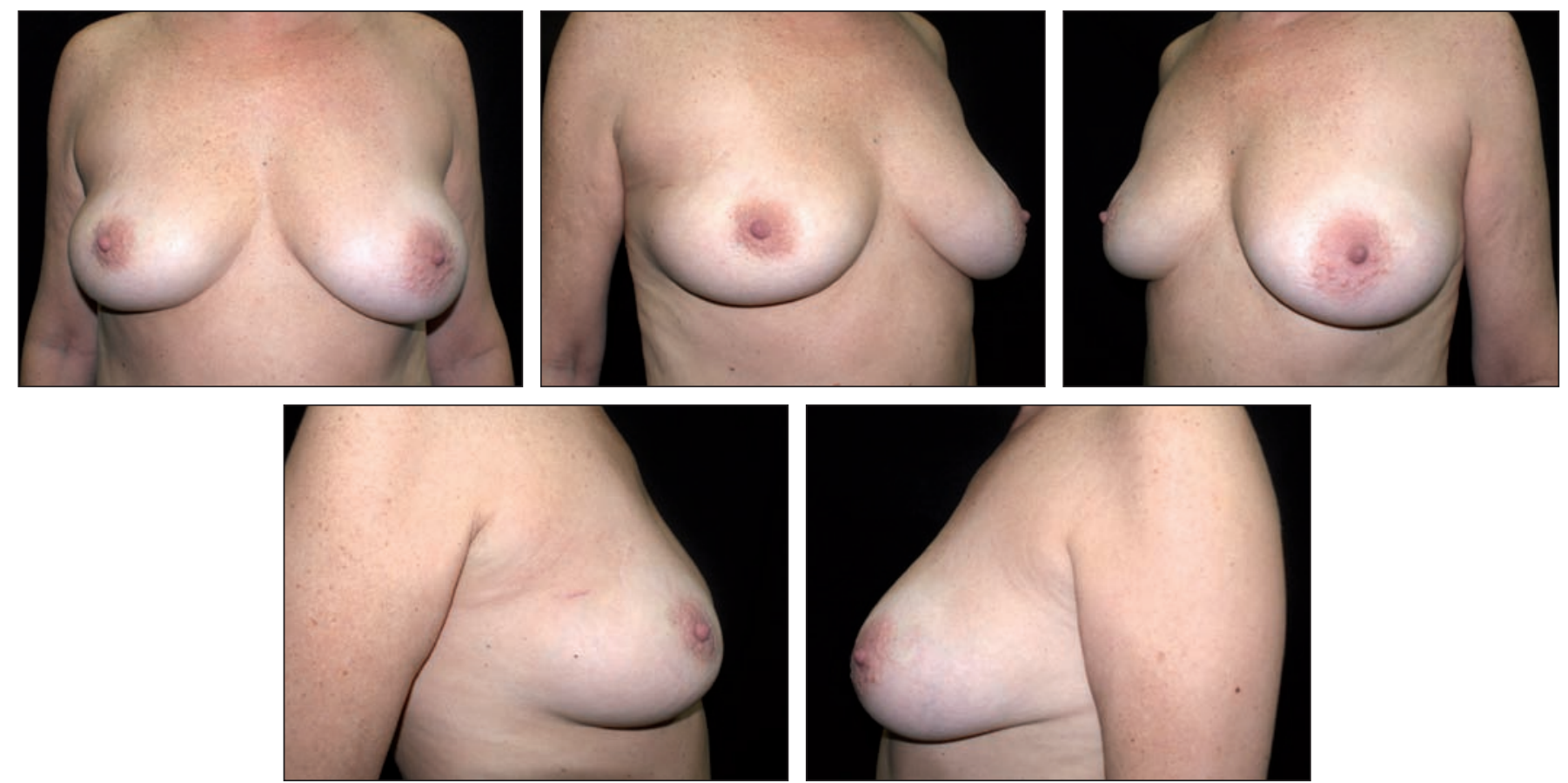

Fig. 7. Paciente de 39 años con recidiva de cáncer de mama derecha tratada 5 años antes con cuadrantectomía y hormonoterapia.
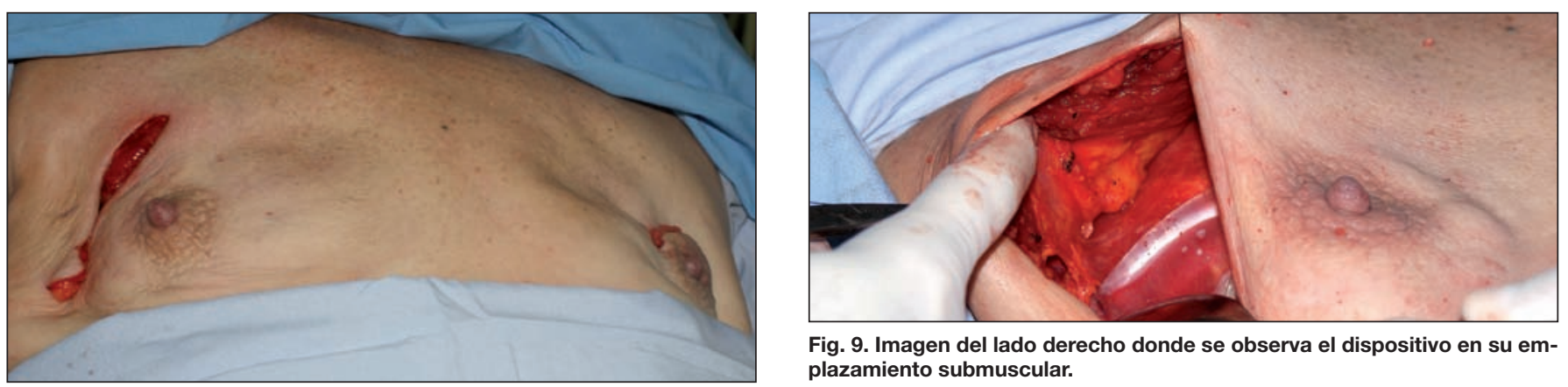

Fig. 9. Imagen del lado derecho donde se observa el dispositivo en su emplazamiento submuscular.

Fig. 8. Mastectomía derecha con conservación de piel y complejos. Biopsia intraoperatoria negativa retroareola-pezón para células malignas. Adenomastectomía profiláctica izquiera. Abordaje derecho por insición previa; abordaje izquierdo por vía periareolar superior para realizar mastopexia.

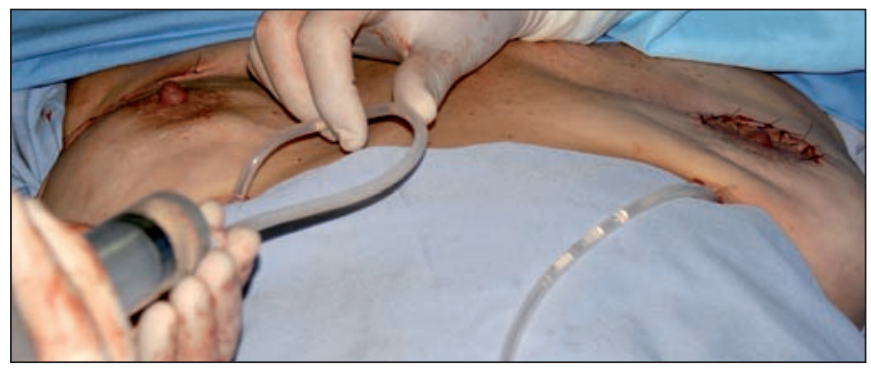

Fig. 10. Sistema bilateral colocado al finalizar el procedimiento quirúrgico. Expansión solo del $20 \%$ para evitar presión sobre los tejidos.
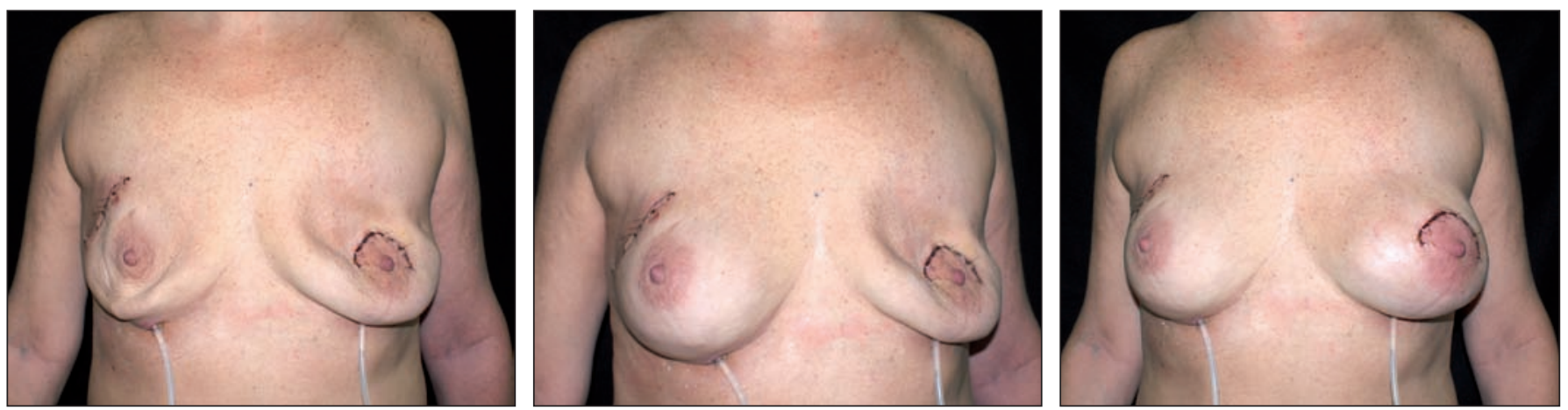

Fig. 11. Control a los 7 días del postoperatorio. Izquierda: al momento de iniciar la expansión (solo expansión del 20\%); medio: al finalizar la expansión del dispositivo derecho; derecha: al completar la expansión del dispositivo izquierdo. Los tubos inferiores son los empleados para llenar los dispositivos. 

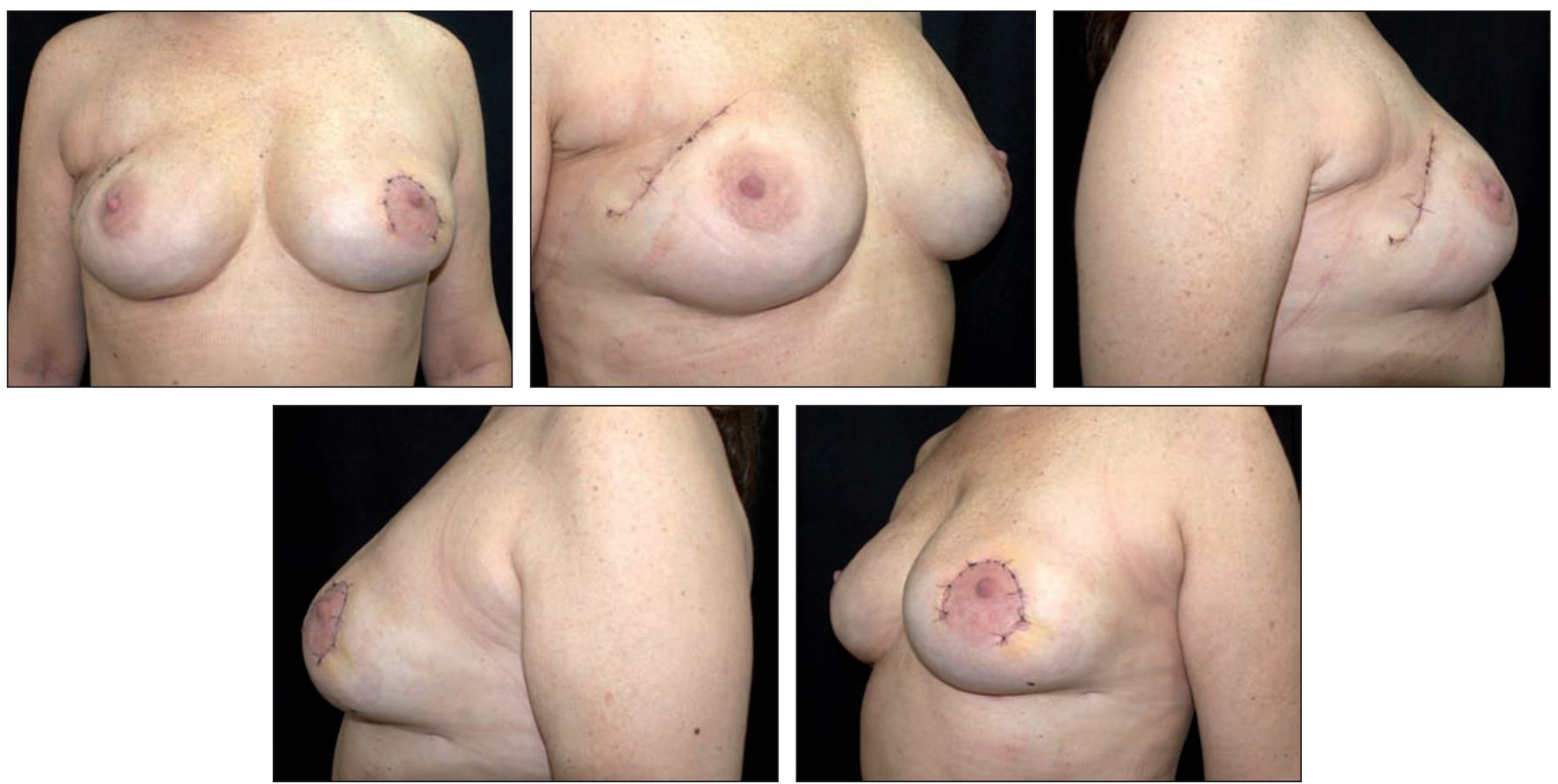

Fig. 12. A los 14 días de completado el segundo procedimiento quirúrgico: retirada de los dispositivos y colocación de los implantes definitivos (Nagor ${ }^{\circledR}$ Cogel 440 XM3 anatómicos) ajuste de los bolsillos submusculares y tamaño definido previamente con la paciente durante la expansión de los dispositivos.

como todos los ajustes necesarios para obtener la mayor simetría mamaria posible.

Este segundo acto quirúrgico se realizó a los 10 días como promedio (entre 8 y 12 días), bajo anestesia con máscara laríngea; procedimos a la retirada de los dispositivos y a la colocación de implantes mamarios definitivos de la misma marca comercial. Los implantes fueron todos anatómicos, con superficie texturizada y volumen de entre 335 y 515 cc., con diferentes alturas $\left(\mathrm{CoGel}^{\circledR}\right.$ system) dependiendo de la anchura y la altura de la mama a reconstruir. En total, 26 implantes $\mathrm{CoGel}^{\circledR}$ XF3 y 34 implantes $\mathrm{CoGel}^{\circledR} \mathrm{XM} 3$. Los volúmenes de los implantes del primer grupo fueron: 16 implantes 405-XF3, 8 implantes $465-\mathrm{XF} 3$ y 2 implantes $515-\mathrm{XF} 3$, siendo el promedio de este grupo de $430 \mathrm{cc}$; en el segundo grupo los volúmenes fueron: 2 implantes 335-XM3, 4 implantes 375-XM3, 18 implantes 440- XM3 y 10 implantes 485XM3, con un promedio de 440 cc (Fig. 12).

En todos los casos libramos la malla de poliglactina 910 a nivel del surco submamario para retirar y colocar el implante definitivo, anclando nuevamente la malla con el mismo material.

\section{RESULTADOS}

No constatamos procesos infecciosos, febriles o eritematosos en las zonas operadas. Las expansiones a los 5 y 7 días se realizaron en el consultorio, con técnicas asépticas, y con solución fisiológica estéril. Todas las pacientes toleraron la expansión completa sin evidencias de sufrimiento de la piel o dolor intenso.

En el momento de decidir el recambio por los implantes definitivos, las pacientes tuvieron la oportunidad de opinar sobre el tamaño final en colaboración con el equipo de Cirugía Plástica, ya que fue sencillo inflar o desinflar los dispositivos expansores con una jeringa de $60 \mathrm{cc}$.

El recambio por los implantes definitivos se realizó a los 10 días (entre 8 y 12 días). En todos los casos procedimos a la toma de cultivos para bacteriología y colocamos los implantes definitivos en el mismo plano en el que se encontraban los expansores.

En 2 casos, el equipo oncológico procedió a efectuar estudio de la región axilar debido a que el estudio anatomopatológico diferido informó de la presencia de carcinoma en la mama contralateral (hallazgo en la pieza de adenomastectomía profiláctica). Este abordaje de la región axilar se realizó por una incisión independiente en axila.

El promedio de duración del segundo procedimiento quirúrgico fue de 60 minutos y el alta hospitalaria en todos los casos se dio a las 24 horas con drenajes bilaterales por contrabertura que se dejaron en promedio 48 horas más. Retiramos los antibióticos cuando se extrajeron los drenajes, excepto en 2 casos que dieron cultivos positivos (Proteus - Gram negativo y Staphylococcus coagulasa negativo- Gram positivo). En ellos, fue necesario comenzar un nuevo esquema de antibioticoterapia con trimethoprim/sulfamethoxazole y ciprofloxacina, $500 \mathrm{mg}$ cada 12 horas, durante 8 semanas. Además, todos los casos siguieron durante 90 días con altas dosis de combinación de Vitamina A y E así como con una dosis de enalapril $5 \mathrm{mg}$ ( 2 tomas por día) para prevenir la contractura capsular (13).

Durante 30 días las pacientes usaron un sujetador compresivo.

Los controles postoperatorios se hicieron a $\operatorname{los} 15,30$, 90 y 180 días (Fig. 13-30).

Los resultados a largo plazo demostraron en este 

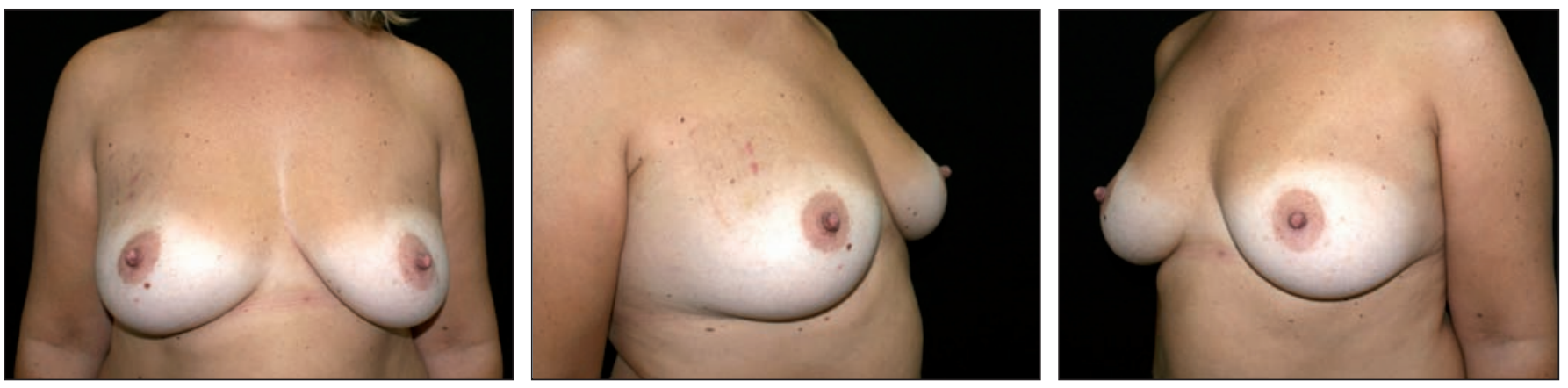

Fig. 13. Paciente de 37 años con carcinoma intraductal de mama derecha diagnosticado por punción en cuadrante súpero-externo y microcalcificaciones mama izquierda.

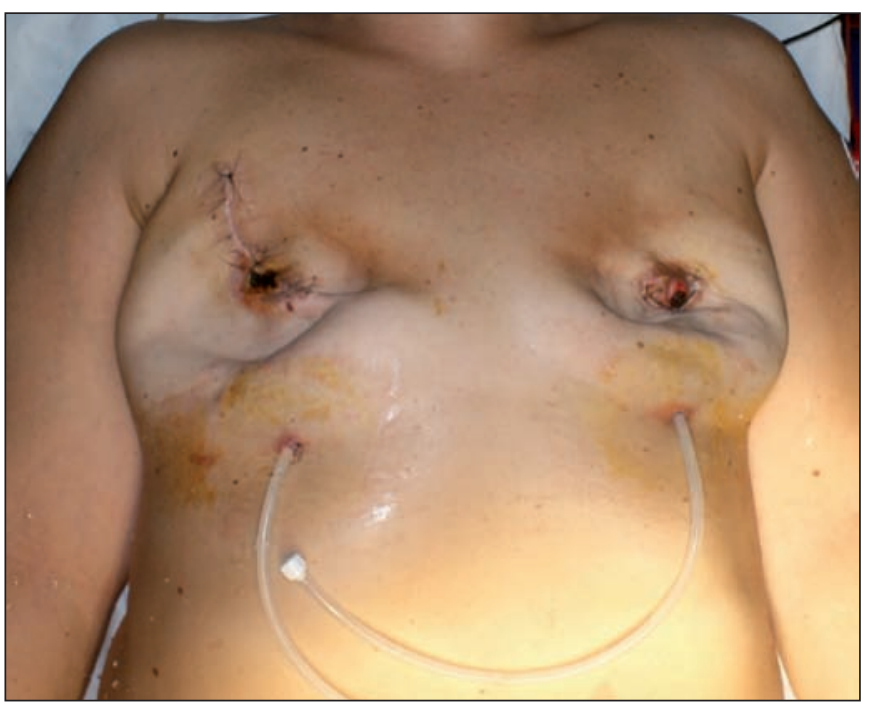

Fig. 14. A los 5 días de postoperatorio: dispositivos expandidos un $20 \%$, mastectomía derecha con conservación de piel (resección de complejo areola-pezón) y adenomastectomía profiláctica izquierda por incisión periareolar inferior.
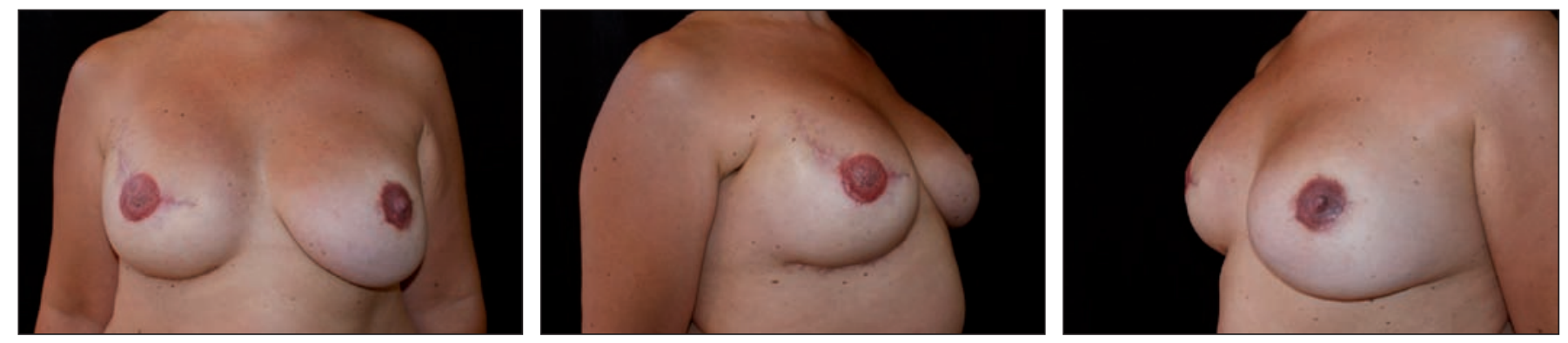

Fig. 16. Resultado final a los 90 días de postoperatorio. Retirada de los dispositivos a los 12 días y colocación de implantes definitivos (Nagor ${ }^{\circledR}$ anatómicos simétricos, Cogel XM3 375). Reconstrucción del pezón derecho con técnica de Star Flap y micropigmentación bilateral para areolas.

grupo de pacientes ausencia de procesos infecciosos, recuperación de su vida social a los 15 días del 2 procedimiento, y aceptación del resultado estético final por parte de todas las pacientes.

Tras 2 años de seguimiento, no hemos identificado casos de contractura capsular.

\section{Discusión}

Cuando se finaliza una reconstrucción inmediata postmastectomía con frecuencia se genera una incertidumbre durante la primera semana, en especial cuando

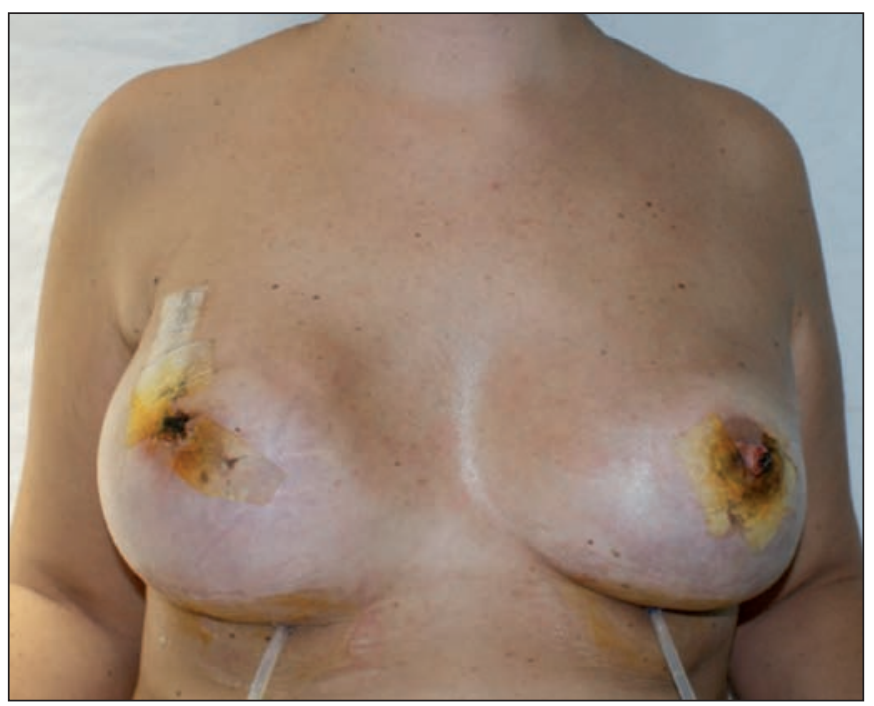

Fig. 15. Expansión completa de los dispositivos a los 7 días de postoperatorio. 


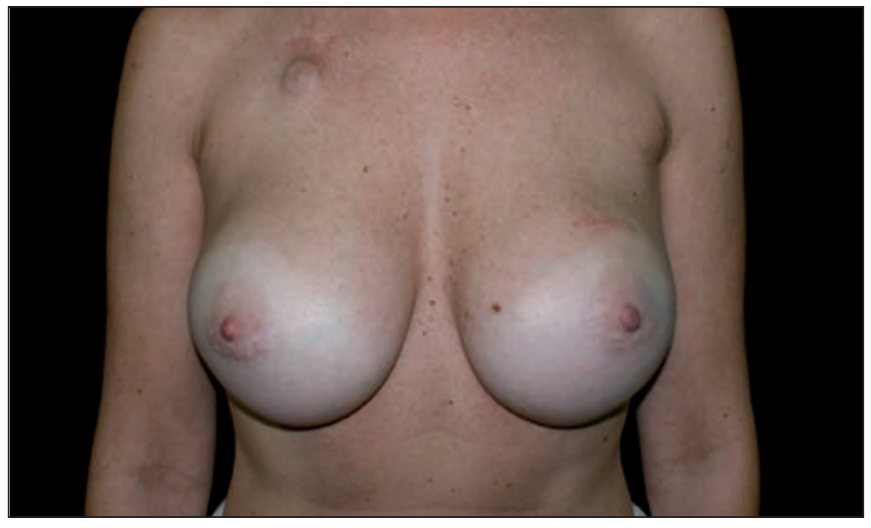

Fig. 17. Paciente con implantes mamarios colocados 12 años, redondos (Silimed® 385 - lisos - proyección alta). Biopsia en hora 12 de mama izquierda con diagnóstico de carcinoma invasor intraductal. Quimioterapia adyuvante a través de reservorio en espacio infraclavicular derecho.

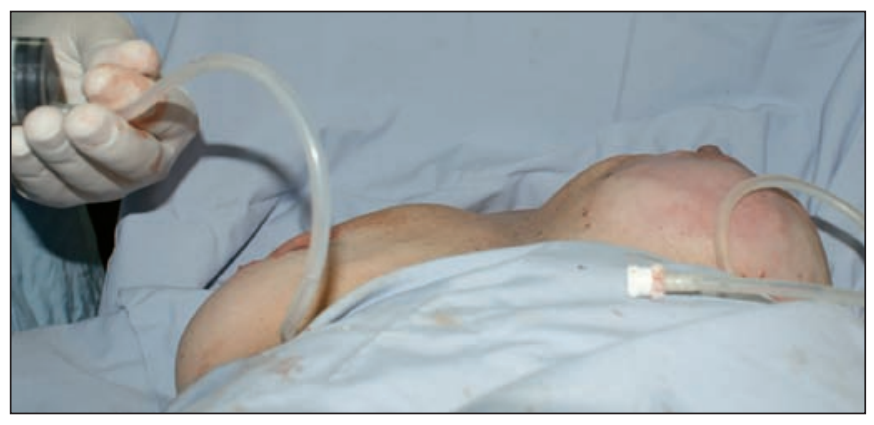

Fig. 19. Intraoperatorio con los dispositivos colocados. Mama izquierda con expansión completa y mama derecha procediendo al desinflado del dispositivo dejando un $20 \%$ del volumen para evitar la presión sobre los tejidos.
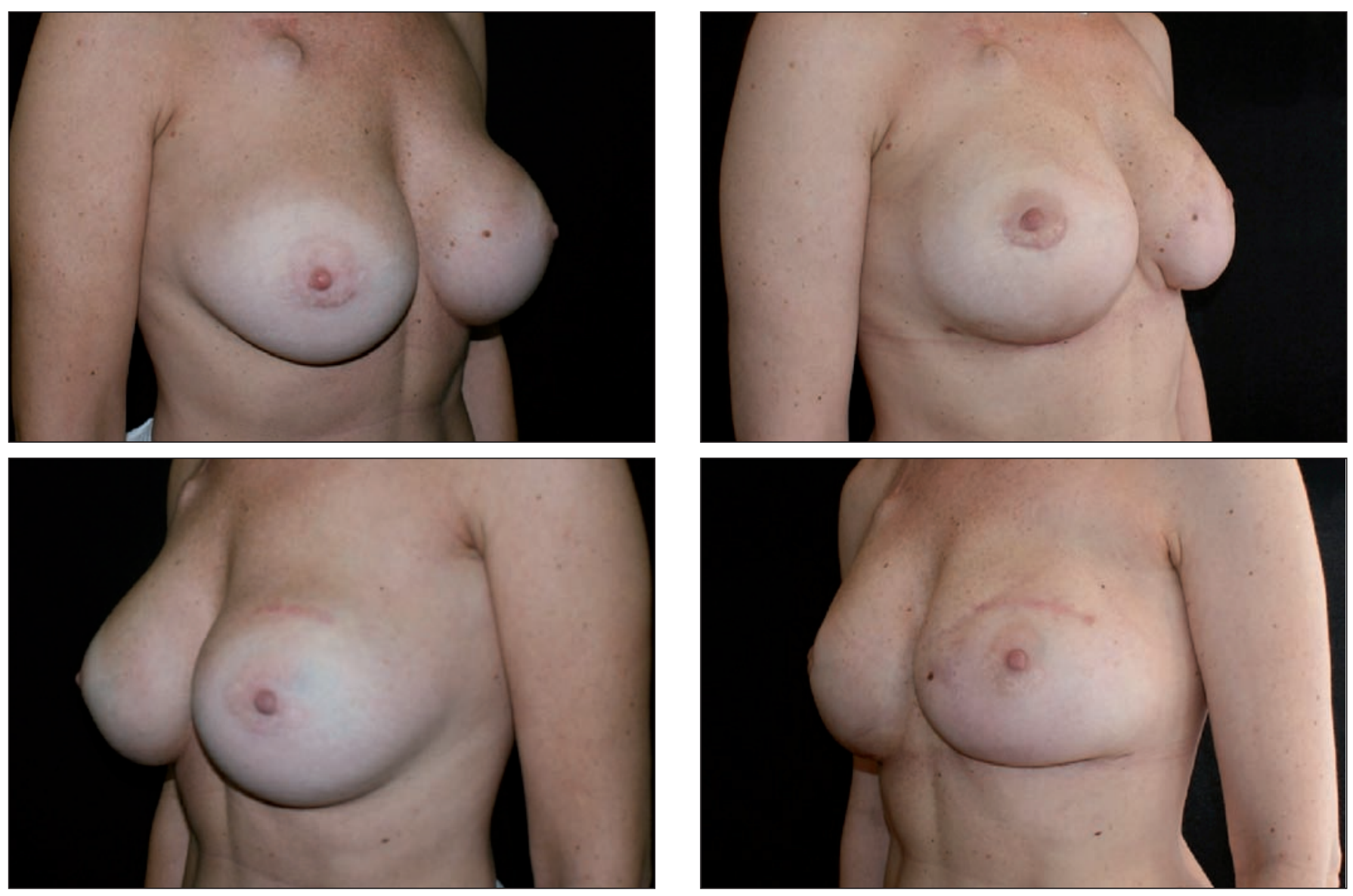

Fig. 21. Resultado final comparativo a los 3 meses. Retirada de los dispositivos y colocación bilateral de implantes definitivos (Nagor ${ }^{\circledR}$, anatómicos, Cogel, XF3 405).

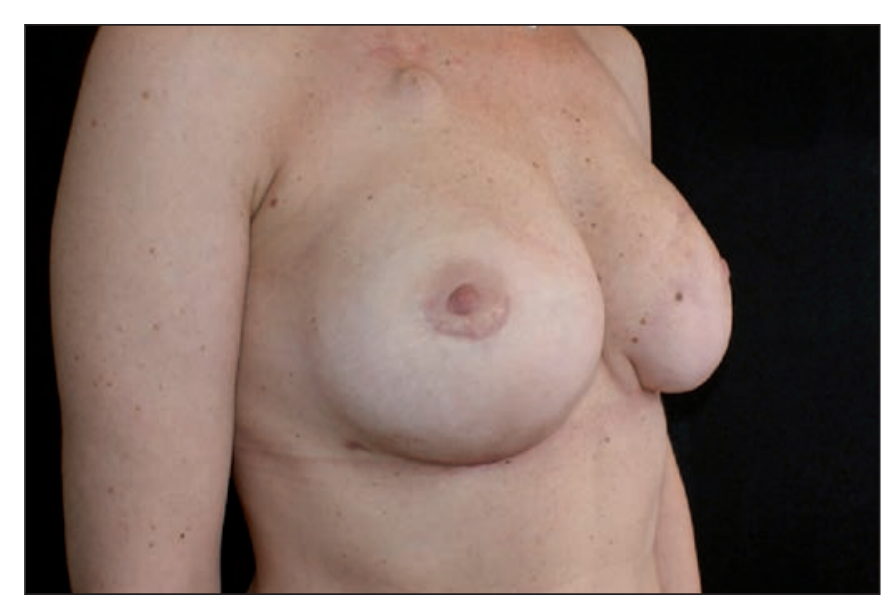

Fig. 18. Intraoperatorio al completar la mastectomía izquierda con conservación del complejo areola-pezón (biopsia intraoperatoria negativa) y adenomastectomía derecha por incisión periareolar inferior.

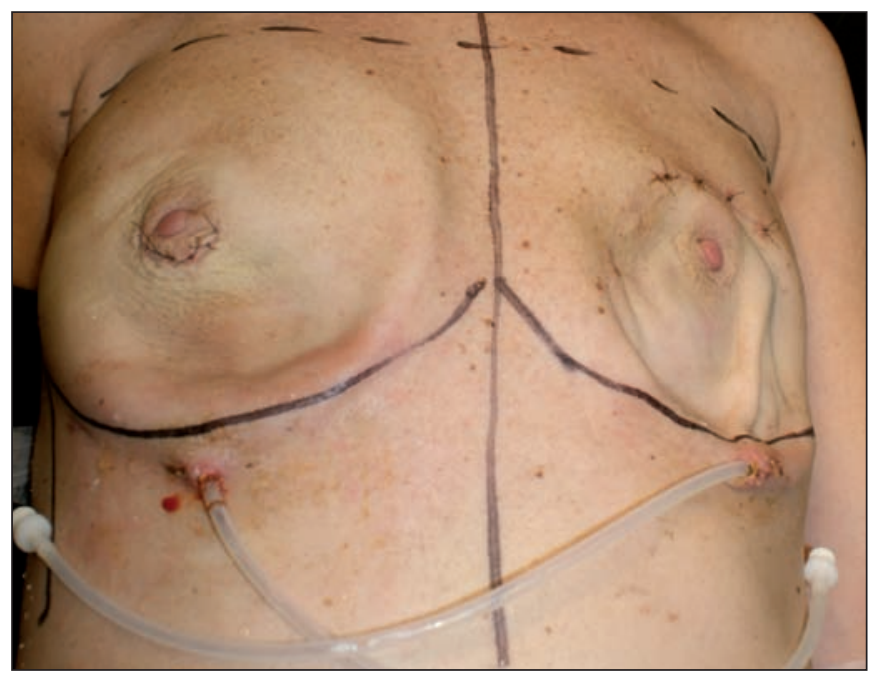

Fig. 20. Imagen al $5^{\circ}$ día de postoperatorio: vitalidad total de los tejidos y dispositivos expandidos solo un $20 \%$

\section{Girugía Plástica lbero-Latinoamericana - Vol. 41 - No 1 de 2015}




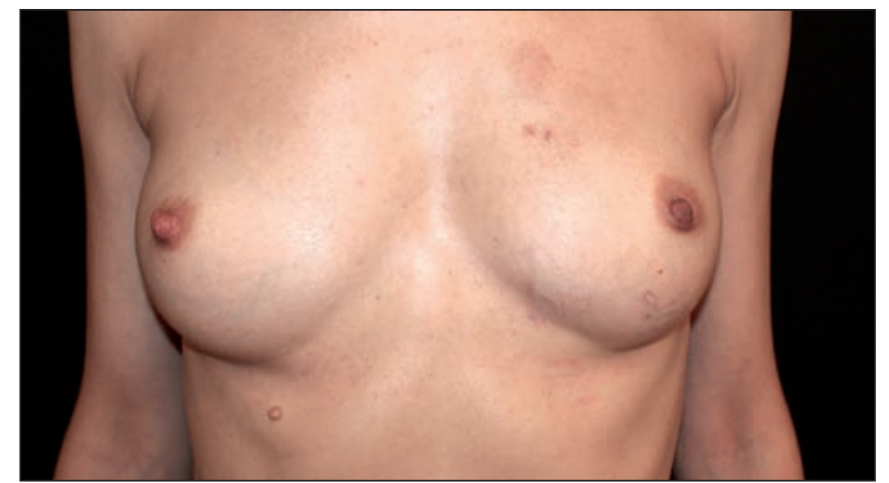

Fig. 22. Paciente de 34 años con biopsia en cuadrante súpero-interno de mama izquierda con diagnóstico de carcinoma lobulillar. Mama derecha densa con microcalcificaciones.

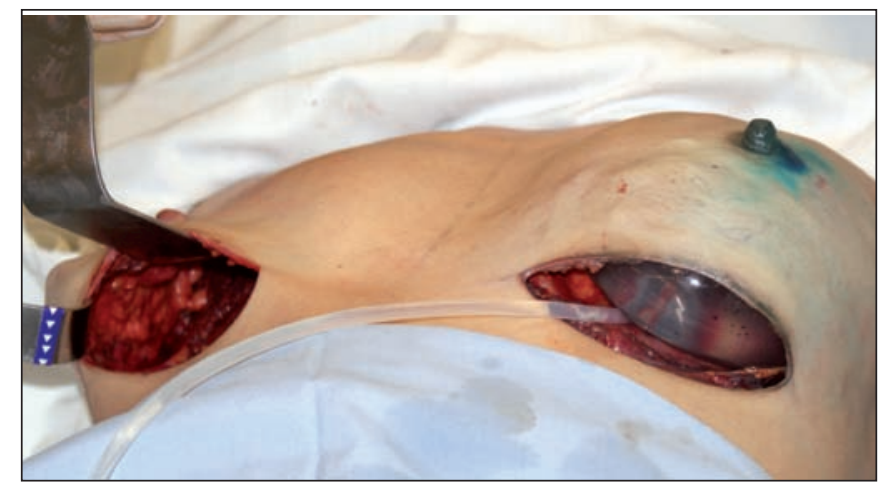

Fig. 23. Mastectomía izquierda con conservación del complejo areolapezón y adenomastectomía derecha reductora de riesgo. Abordaje bilateral por surco submamario. Dispositivo colocado en la mama izquierda.

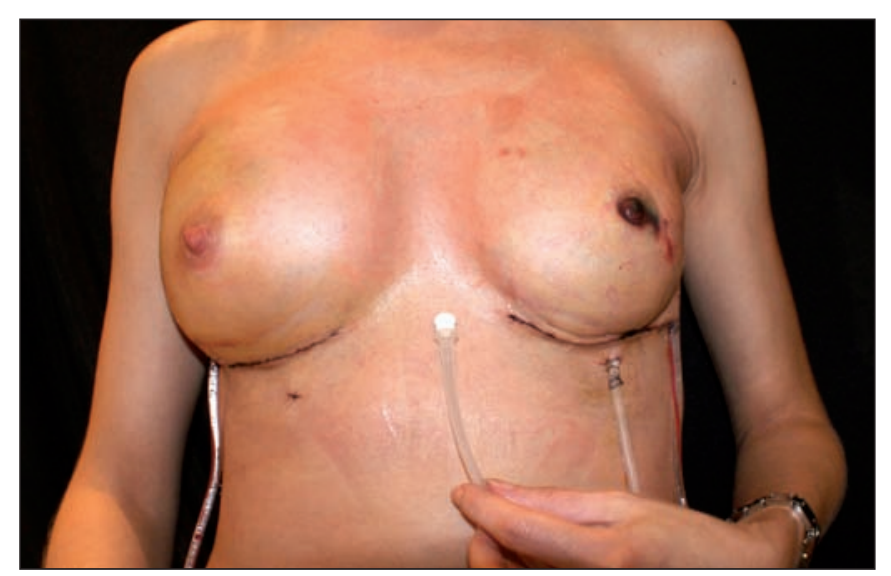

Fig. 24. Imagen a los 7 días de postoperatorio con los dispositivos expandidos al $100 \%$.
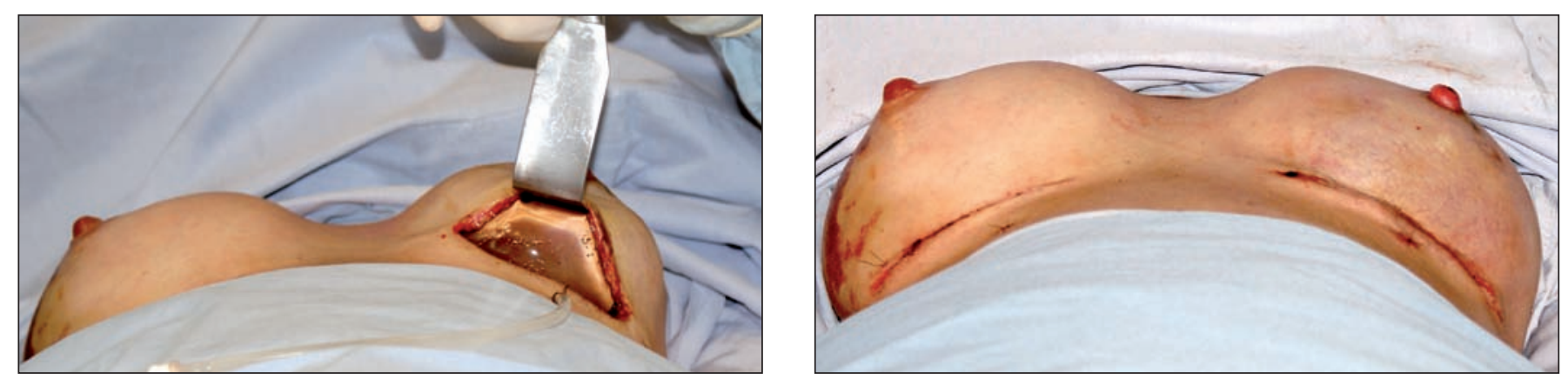

Fig. 25. A los 12 días de postoperatorio, en el momento de efectuar el segundo procedimiento quirúrgico: retirada de los dispositivos y colocación de implantes definitivos.
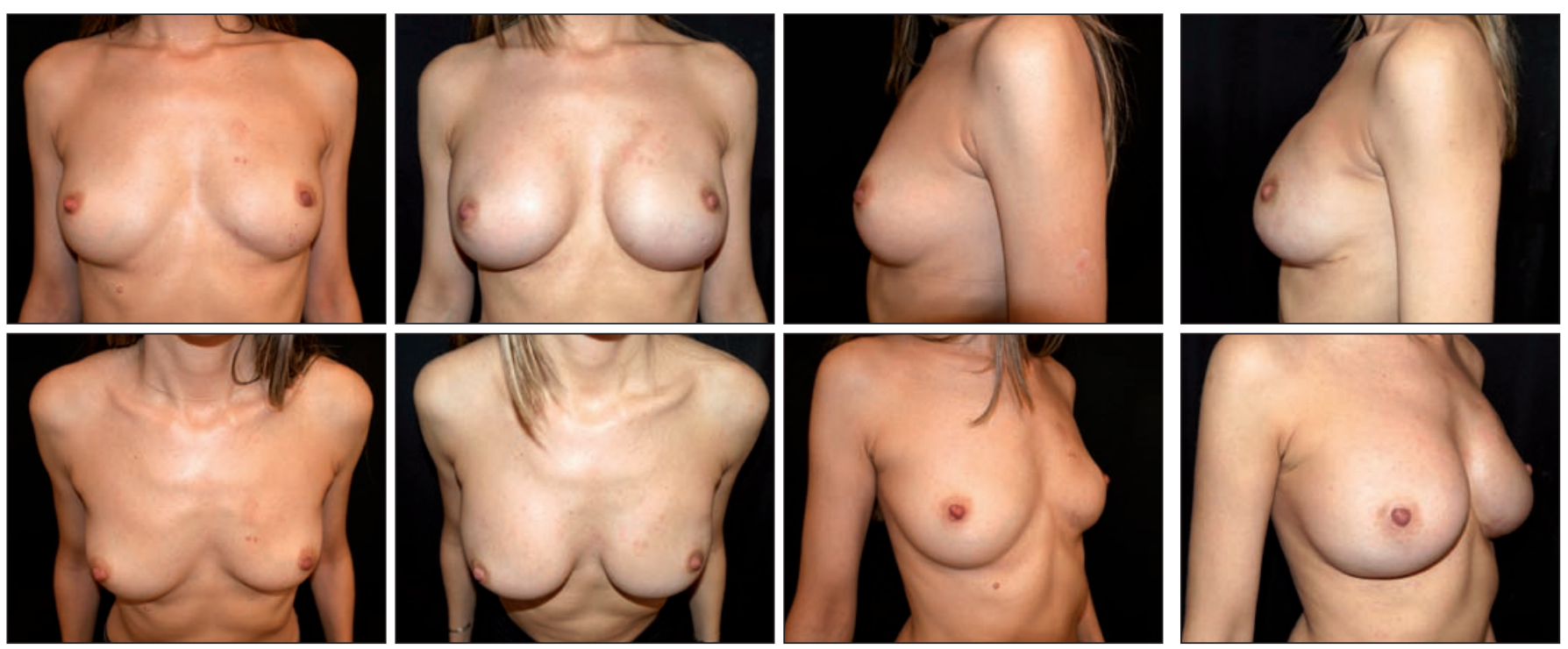

Fig. 26. Resultado final a los 6 meses de postoperatorio. Colocación de implantes bilaterales definitivos (Nagor ${ }^{\circledR}$ anatómicos XM3-440). Volumen final consensuado con la paciente que quería aumentar su volumen primitivo. 

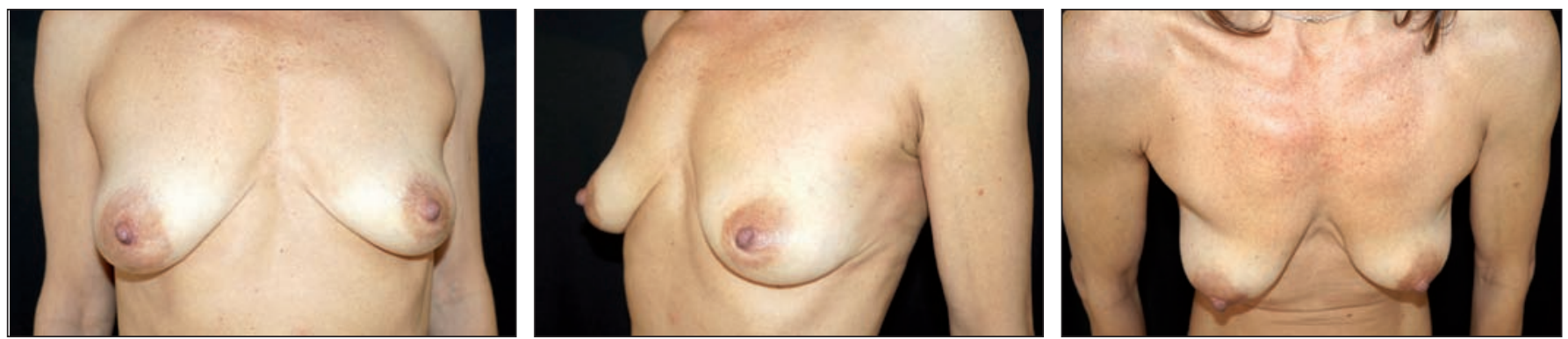

Fig. 27. Paciente de 43 años con biopsia por punción en cuadrante súpero-externo de mama izquirda. Diagnóstico de carcinoma intraductal. Tumor de $2 \mathrm{~cm}$. próximo a la piel. Indicación de adenomastectomía profiláctica derecha por antecedentes familiares directos.

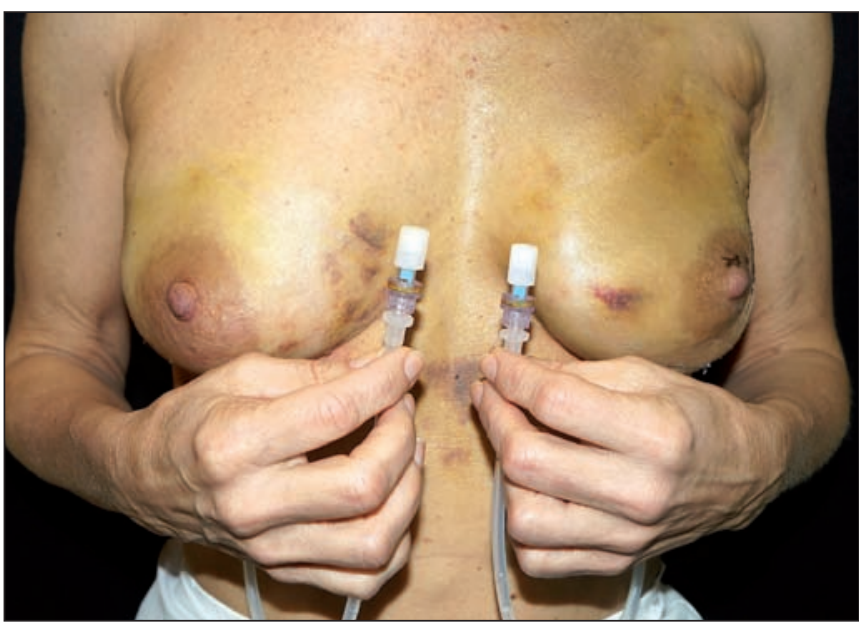

Fig. 28. A los 7 días de postoperatorio con los dispositivos colocados y expansión del $100 \%$
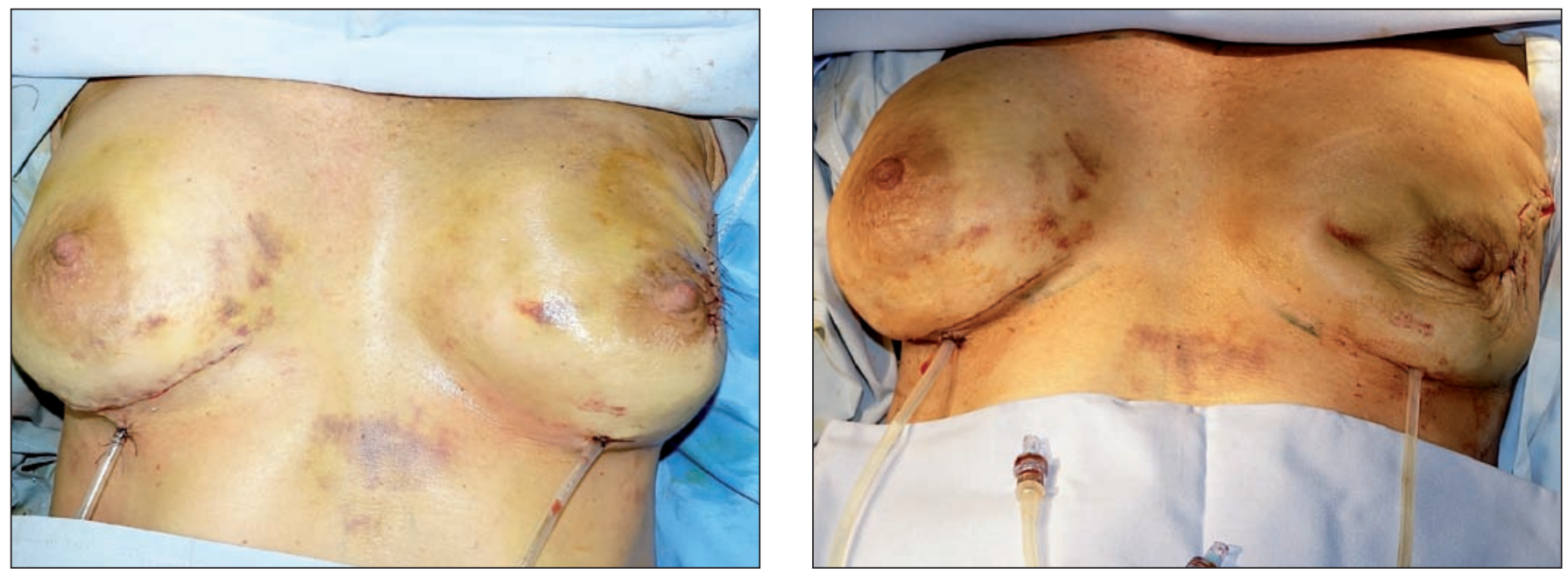

Fig. 29. Segundo procedimiento quirúrgico: izquierda con expansión del 100\%; derecha con desinflado completo del dispositivo izquierdo antes de la retirada de los dispositivos y reemplazo por implantes definitivos.
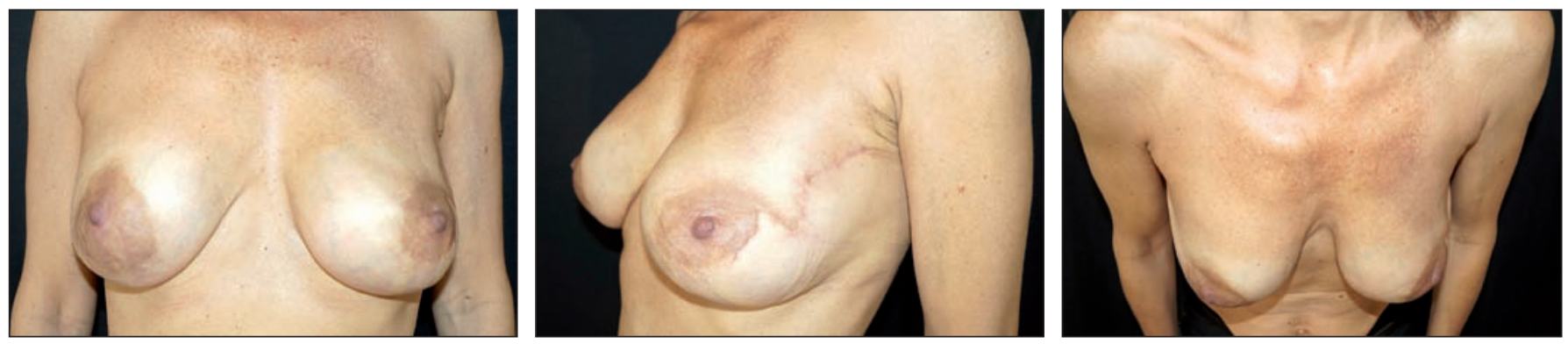

Fig. 30. Resultado a los 180 días de postoperatorio. Se observa cicatriz de incisión en cuadrante súpero-externo izquierdo y zetaplastia para evitar distorsión del complejo areola-pezón. Mama derecha con incisión en surco submamario. Colocación de implantes definitivos bilaterales (Nagor ${ }^{\circledR}$ anatómicos Cogel XM3 375) 
siones que obligan a estudiar la axila. Todo ello hace que entre los 8 y 10 días, debamos decidir las pautas finales de tratamiento.

Lo mismo acontece con la radioterapia; finalizada la cirugía ablativo-reconstructiva desconocemos en numerosos casos si la paciente va a recibir radioterapia postoperatoria. Las indicaciones de radioterapia tras reconstrucción mamaria inmediata han variado en los últimos años, y se toma en consideración el estado ganglionar, el tamaño tumoral y otros factores pronósticos de tipo histológico. El estado axilar, independientemente del tamaño tumoral, con axilas positivas con 1 a 3 ganglios comprometidos o 4 o más ganglios, pueden ser indicación de radioterapia de acuerdo a la experiencia o a los protocolos de tratamiento actuales (14-16).

Estas pautas cobran importancia en relación a la intercurrencia que puede haber en la asociación de expansores y radioterapia. Es sabido que la reconstrucción con expansores y prótesis es la más utilizada en la actualidad (76\% de todas las reconstrucciones mamarias en Estados Unidos) (4) y también son conocidos los efectos negativos de la radioterapia en los resultados cosméticos de estas reconstrucciones en relación al aumento de las complicaciones y a la alta tasa de contracturas capsulares severas (17). La utilización de expansores con válvula metálica incorporada genera también controversia sobre la dificultad técnica que puede generar ésta válvula en la correcta ejecución de la radioterapia y en la homogeneidad de las dosis administradas (18-19).

En centros internacionales, en los casos de indicación de radioterapia una vez recibido el informe anatomo-patológico diferido y después de haberse colocado un expansor con válvula incorporada, hay controversias acerca de cómo tratar a estas pacientes. Ante esta situación, en el Memorial Sloan Kettering de New York, EE.UU., Cordiero y McCarthy (20-21) realizan primero la quimioterapia adyuvante (si está indicada), cambian el expansor por un implante definitivo de silicona lo antes posible y luego realizan la radioterapia. Este orden permite evitar irradiar el expansor con los inconvenientes que esto conlleva, y mantener un resultado más armónico disminuyendo la tasa de complicaciones. Una publicación reciente del Instituto Nationale dei Tumori de Milán, Italia, Nava (22) demuestra que esta conducta de colocar el implante definitivo previamente a la radioterapia disminuye el porcentaje de complicaciones y no incrementa el índice de recidivas locales, en comparación con irradiar el expansor antes de su recambio. Otra alternativa publicada es la propuesta de Kronowitz y Rob del MD Anderson Cáncer Center de Houston, Texas, EE.UU. (23) que consiste en desinflar el expansor tisular, realizar la radioterapia y posteriormente reemplazarlo por una reconstrucción mamaria con tejido autólogo, lo cual conlleva un segundo procedimiento quirúrgico alejado en el tiempo y de mayor complejidad.
El empleo del nuevo dispositivo expansor que presentamos, ofrece a nuestro juicio numerosas ventajas ante estas situaciones complejas:

1. Permite evaluar la vitalidad de los tejidos cutáneos tras mastectomía conservadora de piel y mastectomía de reducción de riesgo (adenomastectomía profiláctica).

2. Reduce la posibilidad de sufrimiento cutáneo ya que al finalizar el acto quirúrgico no se somete a presión a los tejidos (el dispositivo solo se expande en un 20\%).

3. Permite no tomar decisiones apresuradas acerca del tamaño y forma de los implantes definitivos.

4. Facilita el llenado y desinflado muy rápido ya que no posee válvula y el tubo conector es de mayor calibre que el de los expansores convencionales.

5. Posibilita la opinión de las pacientes en cuanto al tamaño de los implantes definitivos.

6. Permite modificar el plan quirúrgico cuando se recibe el informe final de Anatomía Patológica sin sacrificar los logros obtenidos. También que el equipo oncológico realice revisiones, retomas o exploración de la axila durante la segunda intervención.

7. En caso de que sea necesario irradiar a las pacientes, se procedería al cambio del dispositivo expansor por los implantes definitivos en muy corto plazo, sin demorar el inicio de las terapias adyuvantes.

8. Supone un menor coste debido a que estos expansores no tienen válvula remota o incorporada.

\section{Conclusiones}

Presentamos a la comunidad médica un nuevo dispositivo expansor para uso en reconstrucción mamaria bilateral. Este dispositivo es similar a un expansor tisular pero presenta modificaciones en el tubo conector y no tiene válvula. Es de uso exclusivo para los casos en los que se efectúa mastectomía con conservación de piel y mastectomía de reducción de riesgo (adenomastectomía profiláctica), ya que su objetivo es el servir de soporte tisular durante un corto período de tiempo (promedio 10 días) hasta recibir el informe final de Anatomía Patológica y así proceder al cambio por los implantes definitivos, ajustados en tamaño y simetría por este nuevo dispositivo, y sin interferir con o demorar las terapias adyuvantes.

\section{Dirección del autor}

Dr. Ernesto Moretti

Italia 1460

(2000) Rosario, Argentina

correo electrónico: contacto@esteticacentrum.com.ar 


\section{Bibliografía}

1. Rebbeck T, Friebel $T$, Lynch $H$, Neuhausen $S$, van 't Veer L, Garber J, Evans G, Narod S, Isaacs C, Matloff E, Daly M, Olopade O, Weber B: Bilateral prophylactic mastectomy reduces breast cancer risk in BRCA1 and BRCA 2 mutation carriers: The PROSE Study Group. J Clin Oncol 2004; 15:22 (6):1055-1062.

2. Stefanek M.: Risk-reduction mastectomy: clinical issues and research needs. J Natl Cancer Inst. 2001; 5;93 (17):1297-1306.

3. Zakaria S, Degnim A: Prophylactic Mastectomy. Surg Clin North Am 2007; 87 (2): 317-331.

4. ASPS U.S.A. American Society of Plastic Surgeons. Cosmetic Surgery Statistics, 2007. http://www.plasticsurgery.org.

5. Radovan C.: Reconstruction of one breast after mastectomy using temporary expander Plast Surg Forum 1978, 1: 41-44.

6. Radovan C.: Reconstruction of one breast after mastectomy using temporary expander. Plast Surg Surg 1982; 69 (2):195-206.

7. Maxwell GP, Falcone PA.: Eighty-four consecutive breast reconstructions using a textured silicone tissue expander. Plast Reconstr Surg. 1992; 89 (6):1022-1034

8. Becker H.: Breast reconstruction using an inflatable breast implant with detachable reservoir. Plast Reconstr Surg 1984; 73 (4):678-683.

9. Woods JE, Mangan MA.: Breast reconstruction with tissue expanders: obtaining an optimal result. Ann Plast Surg 1992; 47:1461-1466.

10. Custom Fabrication Service, 129 Deerdykes View, Westfield Industrial Estate, Cumbernauld, Glasgow, United Kingdom, enquires@nagor.com,www.nagor.com, 2015

11. CE Certificate-Full Quality Assurance Sysytem - BSI (British Standards Institution): n: CE 02248, Certificate renewal, N: 8125394, 26 de marzo del 2014.

12. Malla Tejida VICRYLtm (poliglactina 910), Ethicon, Johnson-Johnson, www.ni.ethicon.com, 2015. (Ethicon Wound Closure Manual. 2007. Ethicon, Inc.)

13. Zimman O, Tobilli J, Stella I, Ferder M, Ferder L, Inserra F.: The Effects of Angiotensin-Converting Enzyme Inhibitors on the Fibrous Envelope around Mammary Implants. Plast Reconstr Surg 2007; 120 (7): 2025-2033.
14. Albino F, Koltz $\mathbf{P}$, Ling M, Langstein $\mathbf{H}$ : Irradiated autologous breast reconstructions: effects of patient factors and treatment variables. Plast Reconstr Surg. 2010; 126 (1): $12-16$.

15. Ascherman J, Hanasono M, Newman M, Hughes D: Implant reconstruction in breast cancer patients treated with radiation therapy. Plast Reconstr Surg. 2006; 117 (2):359-365.

16. Victor S, Brown D, Horwitz E, Martinez E, Kini V, Pettinga J, Shaheen K, Benitez P, Chen P, Vicini F: Treatment outcome with radiation therapy after breast augmentation or reconstruction in patients with primary breast carcinoma. Cancer. 1998; 82 (7):1303-1309.

17. Benediktsson K: Capsular contracture around saline-filled and textured subcutaneously-placed implants in irradiated and non-irradiated breast cancer patients: five years of monitoring of a prospective trial. J Plast Reconstr Aesthet Surg. 2006; 59 (1):27-34.

18. Moni J: Dosimetry around metallic ports in tissue expanders in patients receiving postmastectomy radiation therapy: an ex vivo evaluation. Med Dosim. 2004; 29 (1):49-54.

19. Barry M: Radiotherapy and breast reconstruction: a meta-analysis. Breast Cancer Res Treat. 2011; 127 (1):15-22.

20. Cordeiro P, McCarthy C: A single surgeon's 12-year experience with tissue expander/implant breast reconstruction: part I. A prospective analysis of early complications. Plast Reconstr Surg. 2006; 118 (4): 825-831.

21. Cordeiro P, McCarthy C: A single surgeon's 12-year experience with tissue expander/implant breast reconstruction: part II. An analysis of long-term complications prospective analysis of early complications, aesthetic outcomes and patient satisfaction. Plast Reconstr Surg. 2006; 118 (4): 832-839.

22. Nava M, Pennati A, Lozza, L, Spano A, Zambetti, M, Catanuto G: Outcome of Different Timings of Radiotherapy in Implant-Based Breast Reconstructions. Plast. Reconstr. Surg 2011; 128: 353-359.

23. Kronowitz S, Rob G: Therapy and Breast Reconstruction: A Critical Review of the Literature. Plast. Reconstr. Surg 2009; 124(2): 395-408. 